\title{
METODOLOGIA
}

\section{A RENOVAÇÃO DA HISTÓRIA: HISTÓRIA DOS SENTIMENTOS.}

\author{
SONIA A. SIQUEIRA \\ do Departamento de História da Faculdade de Filo- \\ sofia, Letras e Ciências Humanas da Universidade de
}

São Paulo.

"A História está na encruzilhada".

Quinze anos passados já sobre as palavras de Braudel (1) cuja sensibilidade acusava a tendência ao arquivamento da História. A morte da História, apontada por Lefebvre, seguir-se-ia à morte de Deus (Nietzsche), à morte do homem (Marx), à morte das ideologias, substituidas pela cientificidade tecnocrática (2).

A História ter-se-ia obscurecido, deixando de ser o centro das preocupações, o nó dos conhecimentos na época atual — a pós-História - onde ainda permanecem sensíveis os sintomas do trans-histórico (3).

$\mathrm{Na}$ realidade a História partilha da crise geral de nossa época. Vive momento decisivo da historicidade: o da rejeição de uma cultura, da busca de novas razões de viver, de nova atividade criadora, da metamorfose da vida cotidiana transformada em obra.

Crise das Ciências Humanas. Crise da História. História colocada entre os produtos fora da moda da razão, na arqueologia do saber.

(1). - "L'apport de l'Histoire des Civilisations" in "Encyclopédie Francaise". T. XX: Le monde en devenir. cap. V. Trad. in "La Historia y las Ciencias Sociales". (Madrid, 1970), 2a. ed. pág. 170. 222 .

(2). - Lefebvre (Henri), O fim da História (Lisboa, 1971. Trad. pág.

(3). - Idem, págs. 238 e 243. 
Em verdade, o mundo contemporâneo está à espreita do que vai fazer o historiador para resolver sobre o destino a dar à História . Aqui o grande desafio: rever a História, destruir a pseudo-História que o homem moderno não quer, da qual ele não precisa: a História que no século passado Ammans Alexis Monteil chamou histoire-bataille, ou Paul Lacombe e François Simiand batizaram de histoire événementielle, presa a uma epistemologia do sensivel, assente no conhecimento sensorial, no senso comum.

Há uma História que não mais satisfaz:

a "história-ciência", tendo por objeto fatos encadeados segundo leis e constituindo séries bem determinadas... uma física social, tendo por modelo a física do século XVIII. A crise do determinismo histórico tornou-se uma crise da História como ciência e ainda mais como modelo de ação" (4).

Só uma historiografia significativa para a cultura humana pode salvar a História, inclusive do risco de ser despojada de seu conteúdo pelas disciplinas vizinhas como a Economia e a Sociologia .

Que tipo de História pode responder a essa necessidade de atualização da cultura? Certamente não uma História prática, que sirva de motivação para atos, orientação para estratégias ou fornecedora de objetivos. Esta sim, tenderia a superar-se, a auto-destruir-se. Desapareceria um referencial: o Passado, o Tempo Histórico, e ficaria um vazio. Tão pouco uma História identificada com o saber absoluto como o queriam Hegel e Marx. O saber esterilizou-se e o conhecimento fragmentou-se indefinidamente.

\footnotetext{
"Se estamos num mundo novo, por que não uma nova História?"
}

Uma História centralizada à volta de uma problemática, não de uma aquisição definitiva. Uma História global. Uma História que compreenda

"os homens que em condições diferentes, e com meios diferentes, no mais das vezes inaplicáveis a nossa época, lutaram por valores e ideais análogos, idênticos ou opostos aos que possuimos hoje" (5).

(4). - Idem, pág. 184.

(5). - Goldmann (Lucien), Ciências Humanas e Filosofia. (Lisboa, 1970). Trad., pág. 22. 
Isto nos dá consciência de fazer parte de um todo que nos transcende, a que no presente damos continuidade e que os homens vindos depois de nós continuarão no porvir.

"A consciência histórica existe apenas para uma atitude que ultrapassa o eu individualista, ela é precisamente um dos principais meios para realizar essa superação" (6).

Somos parte de um todo: a Humanidade. Esta é um yalor universal válido para todos os homens. A consciência disso impele à mudança do conceito do fato histórico que passou a ser tudo o que teve e tem influência notavel na natureza da comunidade: tudo o que ultrapassa o indivíduo para atingir a vida social. Não cabe mais a pura descrição dos fatos. O objetivo da História não é mais

$$
\begin{aligned}
& \text { "dar os acontecimentos do passado como eles na realidade se } \\
& \text { passaram" }
\end{aligned}
$$

como o definira a célebre frase de Ranke. Necessário se torna buscar fatos e conexões novas, inspiradas nas exigências interrogativas do Presente e nas vivências do Passado. História com sua base epistemológica no conhecimento inteligivel.

O que procuramos nos fatos históricos é menos sua realidade material do que sua significação humana (7). O historiador atual está diante do Homem. Do Homem comum, do Homem coletivo.

Conhecer o Homem comum, o Homem coletivo, é o campo da História Social. História Social apoiada na conjuntura como a fizeram Simiand e Hamilton (8). História Social expressa na História quantitativa das estruturas como a propôs Labrousse no seu trabalho sobre a burguesia do século XVIII (9). História Social que não despreze

(6). - Ibidem.

(7). - "Estudar a história - definira-o já a Gestalt — é primeiramente tentar compreender as açöes dos homens, os móveis que os moveram, os fins que perseguiram, a significação que para eles tinham seus comportamentos e açōes".

(8). - Simiand (François), Le salaire, l'évolution sociale et la monnaie. (Paris, 1932); Hamilton (J. Earl), American treasure and the price revolution in Spain 1500-1650. (1934), Money, prices and wages in Aragon, Valencia and Navarra. 1350-1500. (1936).

(9) . - Labrousse (Ernest), Voies nouvelles vers une histoire de la bourgeoisie occidentale aux XVIII et XIXe siècles in "Relazioni. X Congresso internazionale di Scienze storiche". (Roma, 1955). T. IV, pág. 367. 
o quantitativo, mas que tambem ou particularmente se apoie no qualitativo: descrição e medida (10).

A análise do qualitativo postergada a um segundo plano mercê de certa obcessão quantitativista dos historiadores dos últimos decênios, requer novas fontes, novas técnicas e novos métodos. Só assim serão possíveis novas abordagens: soluções para uma História que o tempo atual requer.

Análises novas: a História dos Sentimentos, reclamada por Lucien Febvre ha mais de 40 anos (11) quando pedia uma História da Sensibilidade:

$$
\begin{aligned}
& \text { “... e sensibilidade evoca para nós a vida afetiva e suas ma- } \\
& \text { nifestaçōes...". }
\end{aligned}
$$

Até hoje inexistem uma História do ódio, uma História da crueldade, da alegria, da piedade, do amor. Uma História do Medo esboçada há quase meio século nas Semanas de Sintese de Henri Berr não teve continuadores. Uma História dos comportamentos do homem diante da morte conta com o capítulo Arte de Morrer inserido na Vida cristä sob o Ancien Regime da História literária do sentimento religioso na França, do Abade Brémond (12). Só. E no entanto os sentimentos importam porque estão na base das relações humanas. A análise dos sentimentos importa quando se busca a compreensão do homem global, muito alem das estatísticas, das séries, da frieza "inobjetiva" dos computadores. A análise dos sentimentos importa quando se buscar dominar a História, isto é, buscar a inteligibilidade do Passado, do Presente e do Futuro. Compreender, por exemplo, os sentimentos primitivos in situ, é tambem compreender os sentimentos ressucitados. A História é cheia de ressurgimentos, de ressurreições sentimentais. Porisso o Presente induz a compreensão do Passado.

Se o momento atual consagra a Razão e a Lógica, põe à margem as emoçōes, como secundárias e desprezíveis, os historiadores atuais estão, não obstante, prenhes de ansiedade por uma nova História. História de totalidades. E aqui volta a propor-se outra vez a História dos Sentimentos.

(10). - Soboul (Albert), Description et mesure in histoire sociale in "L'Histoire Sociale. Sources et méthodes". (Paris, 1967), págs. 9-25.

(11) . - Combats pour l'Histoire: "Comment reconstituer la vie affective d'autrefois?" "La sensibilité et l'histoire". (Paris, 1965), 2a. ed. pág. 221.

(12) . - Pierre Chaunu anuncia a elaboração de uma pesquisa de grupo por ele chefiada sobre o problema das atitudes diante da morte no século XVIII francês. In La civilisation de l'Europe des Lumières. (Paris, 1971). 
Um primeiro problema configura-se para o hitsoriador que busca analizar sa sensibilidades:

"onde encontrar o primeiro terreno conhecido das relações inter-individuais da consciência entre os homens senão na vida emocional?... As emoções permitem-nos compreender um pouco melhor a atitude dos homens no passado, e podem definir um método de pesquisa" (13).

Ora, que haverá de mais individual que as emoções? Onde o social? Se as emoções são respostas individuais a estímulos externos, como podem servir para o historiador? Que serviria para a inteligibilidade da Vida, por exemplo, a análise das perturbações orgânicas de um Napoleão encolerizado? Onde o social? Que ficaria para o historiador? A análise do irracional? (14) A volta de uma história de indivíduos? Uma psico-análise retrospectiva? (15)

A solução parece estar na aproximação da história às outras disciplinas que estudam o homem. Neste campo poder-se-ia recorrer à Psicologia Coletiva:

"Assim, pouco a pouco, as emoções associando muitos participantes por sua vez iniciadores e seguidores acabam por constituir um sistema de iniciação inter-jndividual que se diversifica conforme situaçōes e circunstâncias, diversificando-se ao mesmo tempo das reaçōes da sensibilidade de cada um" (16).

As emoçōes são descargas catárticas de sentimentos latentes na comunidade social. Alguns exemplos podem ser elucidativos. O temor dos feiticeiros experimentados pelos nativos do Brasil foi por Nóbrega assim anotado em sua carta aos Padres e Irmãos de Coimbra em 1549:

(13) . - Febvre (Lucien), La sensibilité dans l'Histoire, in "Annales d'Histoire Sociale, t. III, 1941, janeiro-junho, págs. 8-9.

(14). - Jung (C. G.), Two Essays on Analytical Psychology. Archetypes of the Collective Unconscious; Sincronicidade. Um principio não causal de ligação in "Psicologia do Inconsciente".

(15). - Foi o que tentou fazer o médico Gregório de Marañon em seus estudos sobre o Conde-duque de Olivares e Henrique IV de Castela: $E l$ conde-duque de Olivares o la pasión de mandar. (Madrid, 1962). 11a. ed., Ensayo biológico sobre Enrique IV de Castilla y su tiempo. (Madrid, 1957). 8a. ed. $\mathrm{Na}$ mesma linha M. Tereza Oliveros de Castro e Eliseo Subiza Martin publicaram Felipe II. Estudio médico-fistórico. (Madrid, 1956).

(16). - Blondel (Charles), Introduçẫo à Psicologia Coletiva. (Paris, 1932), pág. 197. 
"E acabando de falar os feiticeiros começaram a tremer em seu corpo, que parecem endemoniados, como de certo o são, jogando-se na terra, espumando pelas bocas" (17).

A emoção que se libertava em lágrimas ao ouvir pregadores famosos é um exemplo da fé religiosa latente nos colonos do Brasil do século dezesseis:

"... no fim foi mais veemente e causou tanta dor nos ouvin. tes que ia parecendo aquele sermão o da Paixão, nas lágrimas, gemidos, soluços, e suspiros que davam. Com essa preparação ficou a gente tão molificada para a Paixão, que não foi necessário preâmbulos para tirar devoção. Porque, desde que se começou, até que se acabou, foi um contínuo choro, em gemer e soluçar, de modo que não podiam faze-los calar, por mais que th'o dissessem, tão veemente e grande era o seu sentimento e compaixăo" (18) .

As emoções coletivas - fruto de redução recíproca de sensibilidades diversas - provocam por contágio mimético, o complexo afetivo-motor e associam numerosos participantes. O ódio ao judeu rival na crença, concorente na vida - desencadeou-se na Sevilha do século XIV a um simples incidente: numa igreja um raio de luz incidindo sobre uma imagem deu a impressão dela estar aureolada. Foi o suficiente para incentivar a imaginação de muitos fieis sempre disponíveis a defrontar-se com milagres. Um cristão-novo presente tentou evidenciar a explicação racional do caso. Foi o suficiente para que fosse perseguido aos gritos de hereje e morto em seguida. O fato desencadeou o ódio latente que havia entre os dois grupos - cristãos-novos e cristãos-velhos - e a ele seguiram-se ataques e pilhagens à judiaria da cidade e depois a de outras cidades espanholas (19).

Um segundo problema delineia-se para o historiador que procura captar a sensibilidade como ingrediente da vida social: como conciliar a História dos Sentimentos e a Estrutura social?

(17). - Cartas dos Primeitos Jesuitas do Brasil. Ed. do Pe. Serafim Leite. (Sāo Paulo, 1954), vol. I, pág. 145.

(18) . - Carta do Pe. Antânio Blasques. Bahia, 23-9-1561. In RIHGB. T. XLIX 19 vol. $n^{\circ} 70$. (Rio de Janeiro, 1886), pág. 58.

Conta o referido Pe. Blasques que a emoçāo coletiva parece ter raiado à histeria, com desmaios e gritos táo grandes dos religiosos e seculares que ouviam a prédica que foi preciso o Pe. Provincial mandar suspender o sermão. Op. cit., loc. cit.

(19). - V. sobre o assuntc, Rios (José Amador de los), Historia social, política y. religiosa de los judios de España y Portugal. (Madrid, 1960). L. II, cap. VII, págs. 456-480. 
A estrutura social não é uma disposição de elementos estáticos. Como a vida humana é a uma trajetória de elementos que vem de e vão $a$. A estrutura possui pois seu próprio movimento: é programática (isto é, define-se pelo seu próprio argumento), é constituida a cada momento de Presente, Passado e Futuro (portanto, de vida histórica e social) (20). Isto evidencia a co-implicação da sociedade e da história e a intrínseca historicidade das sociedades. $E$ isto justifica que se possa falar em vida histórica e social.

Captar a História sinonimiza fazer um corte no tempo e no espaço para apreender as situaçóes históricas de uma sociedade determinada num dado momento. Ou acompanhar a evolução dessa sociedade distinguindo seu argumento e nele o que persiste e o que muda. Como? Captando as vigências (21). As vigências sociais repousam nos valores e na hierarquização que a sociedade lhes dá. Entre os valores estão os interesses e os sentimentos (22): valores prático-sensíveis, na classificação de Basch.

Analisar, portanto, os sentimentos em sua expressão social é um caminho de compreensão da convivência e de seus modos. Exemplos?

Em primeiro lugar, o Amor em suas afirmações, distorçōes, variações ou negações, está presente na estrutura empírica da vida humana. A divisão sexuada responde a um modo de instalação de cada indivíduo na sociedade: modo mais profundo que as classes porque afeta o estado mais íntimo das pessoas.

O sexo, analizado deste ângulo, deixa de ser uma simples diferença, mas uma polaridade. A vida humana se projeta a partir do próprio sexo em direção ao outro (23), portanto o amor entre os sexos tem importância para a vida social. Tem significado numa situação concreta, como forma de vida coletiva. Um caso tirado da vida do Brasil do século XVI: João Paris, castelhano, solteiro, bombardeiro, vivia no Pernambuco colonial amancebado com uma bra-

(20). - "Conservação e antecipação são dois ingredientes essenciais de toda estrutura social e se mostram em qualquer secçāo instantânea que nela façamos. Um corte no tempo mostra a temporalidade intrínseca da estrutura, como quando se corta uma veia brota o sangue que por ela circula". Marías (Julián), A estrutura social. Trad. (São Paulo, 1965), pág. 41.

(21). - Usamos a palavra vigência com o sentido técnico que lhe dá a sociologia de Ortega y Gasset: "o que está em vigor, o que tem vivacidade ou forca, tudo o que encontro em meu contorno social e com o que tenho que contar".

(22). - Sentimentos e interesses acabam se entrelaçando, uma vez que estes últimos estão subjacentes nas atitudes emocionais e motoras.

(23). - Marías (Julián), op. cit., pág. 245. 
sila escrava, pagã (24). Que importância pode ter tal fato para a compreensão da vida social? Alguns dados induzem o pesquisador à proposição de problemas sobre a estrutura social. Não importa a afirmação do amor do espanhol pela índia simplesmente, mas importa considerar que João Paris era solteiro e vivia amancebado porque isto implica na forma de matrimônio e de constituição da família, elementos decisivos em toda a estrutura social. Isto propõe como primeiro problema a frequencia estatística dos casamentos, bem como a idade. Brasila, escrava, pagã: problema de nivel pessoal e histórico que condiciona o relacionamento entre os sexos nesses tempos: problema da liberdade na escolha do par. Há no fato um sentido do coletivo caso se possa apurar a frequência com que se repete e, eventualmente, a frequência com que homens de sua profissão vivem em situação semelhante. Mais: o fato tem subjacente uma série de elementos para a compreensão da sociedade pernambucana seicentista. A forma de praticar o amor era o amancebamento. Por que? Pela facilidade de se ter mulher de cor? Pelo pequeno número de brancas presentes nesses tempos da Colônia? Pela atenuação, no Brasil, da điferença entre a forma pública e real do amor?

Antônio da Costa de Almeida, natural da Ilha da Madeira, 36 anos, escrivão da Fazenda del-Rei na Paraiba era bígamo. Casara-se em Lisboa e novamente na Paraiba (25). Maria Simões, natural do Porto, com aproximadamente 40 anos conforme suas declarações, presumira a morte de seu marido na armada de D. Sebastião. Viera para o Brasil e aqui se casara, consumando a bigamia, pois o primeiro marido não morrera (26). Já Pedro Álvares, de 33 anos, carpinteiro, casara obrigado na cadeia de Barcelos com sua criada que

"querelou dele dizendo que ele levara sua virgindade" (27).

Solto, veio para o Brasil onde novamente se casou. Três casos de duplo casamento. A obcessão pelo casamento advinha dos valores do tempo. Para a compreensão da estrutura social conviria indagar a proporção de liberdade de expressão e de comportamento do homem e da mulher (ligando-se a isso o problema da iniciativa), a fugacidade ou a permanência da realidade amorosa, a maior ou menor pretensão ao exclusivismo (que definem o papel do homem e da mulher na sociedade). Em termos de Brasil há de se lembrar o meio pioneiro, a facilidade da convivência, o abrandamento da distância entre os sexos.

(24). - Primeira Visitação do Santo Ofício às Partes do Brasil. Confissóes de Pernambuco. (1594-1595). (Recife, 1970), pág. 132.

(25). - Idem, pág. 58 .

(26). - Idem, pág. 60.

(27). - Idem, pág. 130 . 
O amor em suas distorções tem tambem um significado. Antônio Rodrigues, lavrador, casado, praticou reiteradas vezes o pecado da sodomia (28). A mesma cousa fizeram Sebastião de Morais, 25 anos, solteiro (29), Fulgêncio Cardoso, tratante, 35 anos (casado, mas afastado da mulher) com o irmão (30), e Ana Seixas, mestiça de 25 anos, com o marido (31). Tais atos transcendem ao âmbito do individual; vão alem das sanções religiosas dos confissionários: pressupõem as formas de encontro dos pares, as formas de trato amoroso com suas implicações de testemunhas ou de solidão, as formas de sensibilidade do homem e da mulher. Em termos de sociedade brasileira evidencia uma sensualidade difusa, menor coerção social, um certo esvaziamento de intensidade amorosa. Não se ama de modo idêntico em todos os tempos e em todas as sociedades e sim condicionado pela forma da vida coletiva que impõe um repertório de gestos, emoções e estimativas. Variava no Brasil, em relação à Metrópole, as demonstraçōes do conteudo afetivo do amor? Por que? Por ser um meio pioneiro? Por estarem em moda determinadas faltas? Por que diminuira a pressão social?

Outro capítulo de permanente atualidade: os feitiços, usados como meio de melhor complementação amorosa. E aqui se inserem os filtros de amor, recurso das mulheres de todos os tempos para minorar a própria insegurança ou para alimentar a ilusão de se conseguir dominar o indominavel: os sentimentos alheios. Maria Vilela para conseguir que o marido lhe quizesse bem punha-lhe pó de sapo torrado sob os pés (32). Maria Fernandes deu a Guiomar de Oliveira infalivel receita para garantir a fidelidade do cônjuge: tomasse ela 3 pinhões, neles inserisse cabelos de todo o corpo, mais unhas dos pés e das mãos e raspaduras das solas dos pés. Engulisse os ditos pinhões e depois de expelidos torrasse-os. O pó deveria ser administrado no caldo de galinha (33). Os efeitos eram seguros. Já Maria Gonçalves para que o marido ficasse mais carinhoso administrava-lhe no vinho pós de ossos de defunto de um dia e semen colhido no ato conjugal (34). Dos três casos emerge uma constante: a insegurança da muther branca incapaz de fazer frente à concorrência que lhe faziam as mulheres de cor. Ainda o afeto a distorcer os comportamentos.

(28). - Confissões de Pernambuco, cit., pág. 20.

(29). - Idem, pág. 25.

(30). - Idem, pág. 136.

(31). - Idem, pág. 99.

(32). - Primeira Visitação do Santo Ofício às Partes do Brasil. Confissōes da Bahia. (São Paulo, 1935), pág. 36.

(33). - Confissões da Bahia, cit., pág. 28.

(34). - Idem, pág. 33. 
Um outro sentimento extremamente marcante, a amizade, embora toda ela feita de intimidade e respeito, é condicionada, apesar disso, pelos usos e vigências coletivos. Portanto, integra a forma de vida coletiva e depende de certas condições sociais. Na amizade existe subjacente um pacto tácito de não agressão; as condições de convivência são articuladas pela distância social, isto é, pelas dimensões da vida onde se dá a convivência. Problemas de amizade repontam na documentação inquisitorial: são apôios que se dão os descendentes dos judeus nas suas intermináveis diásporas pelo mundo intolerante dos séculos XVI e XVII. Ou transmudam-se na solidariedade do grupo cristão-novo que aparece mesmo dentro dos cárceres do Santo Ofício.

Eventualmente, depois de longos meses decorridos da prisão, os detidos identificavam seus vizinhos de celas e com eles passavam a se comunicar através de pancadas nas paredes contadas pelas letras do A. B. C. . Inês Lopes, presa pelo Tribunal da Fé em seus cárceres lisboetas, sentindo-se premida a confessar, tomou imediatamente a precaução de avisar seus companheiros do que tinha falado. Assim batendo cautelosamente nas paredes da cela para Diogo Dorta, transmitiu-lhe mensagem que passou por Bento Teixeira e Gaspar Lopes até que as informaçöes pudessem chegar à destinatária, Beatriz Gomes:

"Sua irmã Inês Lopes que está na cela do corredor do meio lhe beija as mâos e lhe faz saber que está confessada e que deu em todos os seus irmãos e irmãs e só em seu marido não. Que lhe pede pelo amor de Deus que vá sem mais detença nenbuma confessar suas culpas" (35).

Havia toda uma política de conduta dentro dos cárceres. Um confessado que acusasse outros, fazia saber o teor de sua confissão, para que o implicado falasse, e assim se lhe desse crédito e por sua vez se resguardasse. Garantia-se, desta forma, a uniformidade das confissões, mantendo-se uma aparência de verdade. E salvava-se a solidariedade do grupo cripto-judeu.

Através das batidas nos cárceres os presos se amparavam e consolavam mutuamente. Principalmente evitavam a angústia da solidão e do silêncio.

O medo da solidão é outro sentimento que preside os comportamentos dentro dos cárceres inquisitoriais. Lutando valorosamente para combater o isolamento, faziam os presos buracos nas paredes das celas.

(35). - ANTT, Inquisição de Lisboa, proc. $n^{\circ} 5.206$. 
"E depois que os guardas a noite visitavam as casas, abriam os ditos buracos e se punham a falar, com um acento tão brando e socegado, que nem os próprios que estavam na casa, seus companheiros, entendiam o que falavam se não chegavam muito perto. E por estes mesmos buracos se casavam alguns com mulheres porque eram buracos por onde se enxergavam muito bem os rostos e se davam e tomavam presentes" (36).

A necessidade de manter a solidariedade do grupo judaico levava os presos da Inquisição a infringir a proibição de contacto com o mundo externo. Apesar de toda a vigilância, parece que os cristãos-novos conseguiam comunicar-se com seus amigos e parentes, dando-lhes conta do termo em que se achavam seus processos, escrevendo em papel ou em panos de linho delgado ou lenço que engomavam, entregando tais escritos aos que deviam sair sentenciados proximamente. Estes, coziam-nos no gibão ou no colchão, e depois, fora do Santo Ofício, entregavam-nos aos destinatários. Através desses escritos os reus aliciavam as testemunhas que nos novos interrogatórios poderiam depor a seu favor, combinando com elas o que deviam dizer para dar toda a aparência de verdade em suas declaraçōes. Mais: através dessas comunicações os presos confiavam aos amigos de fora o nome dos Inquisidores que os haviam de julgar para as providências cabíveis: informavam-se sobre o andamento dos pedidos de perdão geral que constantemente os da nação negociavam com o Rei ou com o Papa. A possibilidade de proclamação de um desses perdóes era motivo para que continuassem as negativas de confissão por parte dos reus.

Algumas cautelas tinham os presos nesses documentos que emanavam dos cárceres. Usavam linguagem toda especial, que devia ser compreendida apenas pelos judeus. Pelo menos assim o criam, parece-nos que com boa dose de ingenuidade. Um exemplo:

"Sabereis que o nosso Troiano é na realenga a negociar com a Aguia de bico revolto aquilo que menos temos e de que mais havemos necessidade"...

que, em outras palavras, significava:

(36). - ANTT, Inquisição de Lisboa, proc. n 5.206 cit.

O relatório é de Bento Teixeira, que contou aos juizes da fé ter, através desses buracos, prometido, diante de cinco testemunhas, que saindo dos cárceres casar-se-ia com Maria Henriques de Salvaterra, obrigando-se ambos, com solene juramento e promessas. Da mesma maneira combinaram casamento Afonso Fidalgo e Margarida Lemos. Ibidem. 


\begin{abstract}
"Sabeis que o nosso Heitor Mendes está em Madrid a negociar com el-rei Felipe a nossa liberdade" (37).
\end{abstract}

Essa coesão grupal dos cristãos-novos e dos cripto-judeus de que temos inúmeros exemplos nos paises ibéricos, fica a evidenciar um certo grau de radicalismo social, uma ausência de respeito a determinadas crenças que levaram, no isolamento defensivo do grupo, ao reforçamento da amizade.

No Brasil-Colônia são frequentes os jantares e conversas que aproximavam os amigos. Formavam-se pequenos círculos de composição diversa dos encontrados nas províncias metropolitanas. As condições sociais da Colônia definiam outro grau de proximidade da vida e automaticamente diluiam hierarquias e reduziam distâncias sociais. Influiam nas amizades. $\mathrm{E}$ as amizades orientavam as vidas.

Já o sertão despertava nos mamelucos sentimentos de lealdade à raça materna. E muitos deles quando lá estiveram tingiram as próprias peles, passaram a ter muitas esposas, adotaram nomes índios, entregaram-se às cerimônias dos fumos (38).

Num outro extrcmo, o ódio, o desejo de vingança, pontilham a vida colonial brasileira. Domingos Barbosa afirmava em Pernambuco que se o seu vizinho Manuel de Leão não the pagasse $2 \$ 000$ havia de lhe dar muita pancada e quebrar a cabeça onde o achasse (39). Manuel de Leão afirmava para quem o quizesse ouvir, que ainda que arrenegasse a fé havia de se vingar (40). Violante Pacheca dizia que Deus não seria Deus se não a vingasse do marido, e de uma mulher por quem ele dava nela (41). No prosaico dos fatos transparecem conflitos sociais motivados pelo dinheiro, arestas do relacionamento entre cristãos-velhos e cristão-novos, a coerção religiosa sobre as consciências, os problemas do amor conjugal em crise num meio lasso e tolerante.

(37). - ANTT, Inquisiçâo de Lisboa, proc. nค 5.206 cit.

(38) . - Vejam-se, por exemplo, as confissōes dos mamelucos Pero Bastardo e João Fernandes em Pernambuco e de Rodrigo Martins, Manoel Branco, Tomaz Ferreira, Francisco Afonso Capara, Lázaro da Cunha, Antônio de Meira, Domingos Rabelo, Braz Dias, André Dias, Paulo Adorno e Tomacauna, na Bahia. In Confissōes de Pernambuco, cit., págs. 28 e 45; Confissões da Bahia cit. págs. 93, 96, 97, 98, 107, 117, 118, 121, 134, 157 e 167, respectivamente.

(39). - Confissĩes de Pernambuco, pág. 30.

(40). - Confissões de Pernambuco, pág. 30.

(41). - ANTT, Inquisição de Lisboa, proc. $\mathrm{n}^{9} 10.747$. 
A desconfiança aparece com relativa frequência nas declaraçōes dos colonos. Braz Fernandes dizia, desenvoltamente, que os papas passavam bulas para ganhar dinheiro e que

"de frades e cléricos ainda havia de se perdem o mundo" (42).

\section{Simão Pires Tavares em muitas vezes}

"cm lugares e tempos diferentes, perante muitas pessoas"

disse que as ofertas que se davam aos clérigos nas igrejas pelos ofícios não aproveitavam às almas. Não seria pelo cantar dos clérigos que as almas iriam à glória (43). De tais biliosas exclamações afloram os conflitos latentes na sociedade em que eram claras as dúvidas sobre a posição do grupo clerical. Tais abalos adviriam da ignorância doutrinal dos padres, de seu pouco canônico comportamento ou da defasagem entre suas palavras e exemplos.

Do sentimento religioso está toda entremesclada a vida da Colônia. A Fé penetrava em tudo em suas afirmações ou em suas negaçōes, mostrando o elemento religioso como componente da estrutura e da estratificação social. Assim, Simão Tavares ofereceu-se aos demônios (44). A mameluca Domingas Gonçalves desafiava o Crucifixo por ter dor de dente: se Deus não lhe tirasse tal dor, não seria Deus (45). Francisco Cortes arrenegava a Deus por ter perdido no jogo (46). Afonso Luis dava dedos ao diabo para que ele o livrasse da mulher que o maltratava (47).

Numa ânsia de desvendar mistérios ou cousas ocultas entregavam-se os homens à prática de adivinhaçōes, aceitando embora a idéia de pactos com o demônio que estaria por trás das adivinhaçöes como das feitiçarias e superstições. Cousas advindas da grande disponibilidade para crer. Assim Antônio da Costa, na Bahia do século XVII, tendo sido roubado em dois pares de meia de seda e um corte de gibão, desejoso de saber o nome do ladrão, recorreu a Ana Coelha que a rogo e mandado dele fizera diante de si a feitiçaria a quem chamam das Horas de Nossa Senhora

(42). - Confissões de Pernambuco, pág. 33.

(43). - Idem, pág. 24.

(44). - Confissóes da Bahia, pág. 42.

(45). - Confissóes de Pernambuco, pág. 31.

(46). - Confissóes de Pernambuco, pág. 36.

(47). - ANTT, Inquisição de Lisboa, proc. $\mathrm{n}^{\circ} 16.895$. 


\begin{abstract}
"abrindo o livro, meteu uma chave de cadiado no meio ficando a maior parte da chave de fora $e$ fechando as horas com as brochas poz um dedo na chave e com o dedo de um menino seu filho posto tambem na chave de modo que ficava o livro no ar e nomeando-lhe ele confitente as pessoas em que tinha suspeita do furto que the fizeram dera o livro de volta no tempo em que fora nomeado um negro da terra. E logo a dita Ana Coelha dissera que aquele era o que tinha cometido o dito furto" (48).
\end{abstract}

Francisco Nogueira recorreu a um negro escravo dos franciscanos para saber como acharia uma cativa que lhe fugira a três meses, sendo-lhe informado que a negra voltaria no prazo de quinze dias o que de fato sucedeu (49).

Ainda um outro sentimento a condicionar as perspectivas da vida: o sentimento diante da morte. Determinar o grau de probabilidade com que o sentimento da morte impregna cada sociedade é imprescindivel para entender sua forma de vida e toda uma série de comportamentos humanos. A aceitação coletiva da morte ou a sua contenção dentro de determinadas fronteiras resulta e origina diferente sensibilidade vital, e influi no modo do indivíduo se instalar na vida.

Define-se parcialmente a estrutura social pela realidade que a morte possui dentro dela. Se o sentimento da morte é suplantado por outros como o da honra - como aconteceu na Espanha dos Séculos de Ouro - isto vai explicar a menor resistência da sociedade às ações violentas ou o tom dos escritores referindo-se a execuções. Um exemplo: a carta do verdugo Alonso Ramplón a seu sobrinho Pablos, relatando como acabara de enforcar seu pai e quão galhardamente este se portara. Ou as descriçōes da execução de D. Álvaro de Luna, deposto valido de Henrique IV de Castela:

"No meio da praça daquela vila haviam levantado um cadafalso e posto nela uma cruz com dois candelabros e debaixo um tapete. Subiu no cadafalso, fez reverência à cruz. Dados alguns passos entregou a um seu pagem que ali estava o anel de selar com estas palavras - Isto é o último que te posso dar - -0 moço gritou com grandes soluços e pranto, ocasiāo que fez saltar lágrimas a muitos por causa dos vários pensamentos que lhes acudiram com aquele espetáculo. Comparavam a felicidade passada com a presente desgraça, cousa que até a seus inimigos fazia gemer e chorar. Achava-se presente Barrasa, cavalariço do príncipe D. Henrique. Chamou-o D. Alvaro e the disse - Ide e

(48). - Confissões da Bahia (1618), pág. 447.

(49). - Idem, pág. 432. 
dizei ao Príncipe, de minha parte, que no gratificar aos seus criados não siga o exemplo do Rei seu pai. Viu um garfo de ferro cravado num madeiro bem alto. Perguntou ao verdugo para $a_{t}$ que o haviam posto ali. Respondeu-lhe que para por ali sua cabeça depois de cortada. Acrescentou D. Alvaro: Depois que eu morra faz do corpo o que tiveres vontade, que ao varão forte nem a morte pode ser afrontosa, nem antes do tempo. Disse isso e desabotoando o vestido, sem mostra de temor abaixou a cabeça para que a cortasse no dia 5 do mês de julho.

Ficou o corpo sem cabeça pelo espaço de 3 dias no cadafalso, tendo perto uma bacia para recolher esmolas com que enterrar um homem que pouco antes se podia igualar aos reis: assim se mudam as coisas"...

Se a fidedignidade do relato foi alterada pela forma literária, a atitude do valido diante da morte foi corroborada por outros cronistas de Henrique IV (50). E o autor do texto (51) tranpôs para ele a maneira com que os homens de seu tempo encaravam a morte: valor subsidiário diante da lealdade ao soberano, da certeza da vida transcendente, das virtudes pessoais do nobre.

A presença da morte norteou a vida daqueles homens do século XVI e XVII. Lembrar tal presença foi o leit-motiv dos principais homens de letras como Jorge Manrique (52).

Novas análises históricas implicam em novas fontes. Onde buscar dados sobre o mental coletivo, sobre os sentimentos - dados que possam ser interpretados socialmente?

Não pensamos numa História do Amor, por exemplo, pelos tempos, através de civilizações: apenas propomos um caminho de pesquisa sobre os sentimentos fundamentais do homem, sobre suas modalidades, sobresuas aceitações e recusas sociais. Semelhantes informações en-

(50). - Veja-se, por exemplo: "Crónica de Enrique IV escrita en latim por Alonso de Palencia" - tradução castelhana de A. Paz y Nelia (Colección de escritores castellanos) Madrid, 1904-1908. 4 volumes.

(51) . - Morte de D. Álvaro de Luna: Pe. J. de Mariana in Historia de España, libro XXII, 12-13.

(52). - Recuerde el alma dormida/ Avive el seso y despierte/ Contemplando/ Como se pasa la vida/Como se viene la muerte/ Tan callando/ Cuan presto se va el placer/Como después de acordado/ De dolor/ Como a nuestro parecer/Cualquiera tiempo pasado/ Fué mejor.

Coplas de Jorge Manrique a la muerte de su padre D. Rodrigo. 
contram-se em documentos morais, como os arquivos judiciários (53); em documentos artísticos como as artes plásticas e a música (54), e principalmente na literatura, tão pouco usada ainda pelos historiadores.

Novas fontes, novos métodos, novas técnicas devem conduzir à consecução de uma História Global.

Se dominar a História é buscar a inteligibilidade do Passado, repetimos, Presente, Futuro, compreender os sentimentos primitivos in situ é tambem compreender os sentimentos ressucitados. E a História é cheia de ressurgimentos, de ressurreições sentimentais (55).

A Sensibilidade na História merece uma pesquisa, uma larga poderosa, coletiva pesquisa, conforme palavras de Febvre há quase meio século.

Historiar a Sensibilidade é tambem fazer historia: pois leva a compreender o homem, o homem global.

(53). - Sobre os arquivos judiciais trabalhou Robert Mandrou analisando as mudanças de mentalidade na França do século XVII no seu já famoso "Magistrats et sorciers en France au XVIIe. siècle. Une analyse de Psychologie Historique". Paris, 1968.

(54). - Veja-se, por exemplo, como contribuição à compreensão da cultura do tempo trabalhos como "O rock o mito e o grito. A musica pop como uma forma de comunicaçāo e de contra-cultura" de Roberto Muggiati (Ed. Vozes, 1973) ou o trabalho dos alunos da Universidade Católica de Minas Gerais: "Eu năo sou cachorro não" (1973).

(55). - Não seriam disso excmplos os cultos de sangue, os cultos das forças elementares ou os cultos do sol que reaparecem nas religiōes afro-brasileiras, ou mesmo nos campings? 